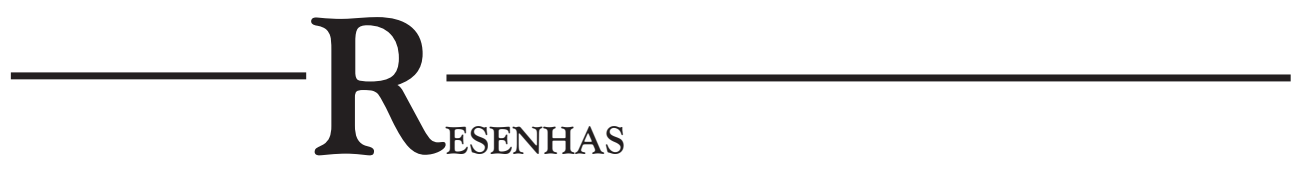

BANAGGIA, Gabriel. As forças do Jarê: Religião de matriz africana da Chapada Diamantina. Rio de Janeiro: Garamond, 2015, $344 \mathrm{pp}$.

Iacy Pissolato Silvera

Universidade Federal da Bahia

Salvador - BA - Brasil

Orcid: https://orcid.org/0000-0002-2316-0301

Marina Guimarães Vieira

Universidade Federal da Bahia

Salvador - BA - Brasil

Orcid: https://orcid.org/0000-0002-8676-4655

\title{
MANTENDO VIVA UMA FESTA SEM FIM
}

O livro As forças do Jarê: Religião de matriz africana da Chapada Diamantina apresenta-se como uma obra importante para o campo da antropologia da religião. Escrito por Gabriel Banaggia, fruto de sua tese de doutorado pelo Museu Nacional, o autor apresenta a descrição do Jarê, religião ainda tão pouco conhecida e pesquisada. Descrito com base na experiência do autor na cidade de Lençóis, especialmente a 
partir do olhar e convívio masculino como condicionante em campo, conforme ressalta o autor, essa religião é apresentada aos leitores a partir de histórias do passado e de eventos presentes rituais e cotidianos da dança, dos tambores, da negritude e dos modos de viver negros, dos caboclos, do passado garimpeiro, mas também do momento presente, de resistência desses praticantes religiosos. $\mathrm{O}$ autor retrata, assim, um jogo de forças sempre em movimento de contingência ou fortalecimento em que agenciam humanos e não humanos, bem como as histórias do passado, as forças do presente e a manutenção para a continuidade futura.

Em uma proposta inspirada na intenção comparativa de Bastide entre as religiões de matriz africana no Brasil surgidas da diáspora negra, Banaggia descarta quaisquer comparações de cunho evolutivo, como as tentativas anteriores, e propõe considerar suas diferenças enquanto transformações umas das outras, constituindo um continuum heterogêneo. Conforme destaca o autor, a utilização do termo "matriz" remete não só ao vínculo genealógico com uma África originária (real ou imaginária), mas também com o referente matemático que evidencia arranjos e transformações entre elas.

Em um trabalho de campo desenvolvido por quatorze meses, sendo doze desses ininterruptos, vivendo na cidade de Lençóis, Gabriel Banaggia visitou cerca de quinze casas de Jarê e participou de aproximadamente trinta celebrações rituais, aprofundando seu trabalho de campo em três casas. Entretanto, como é destacado pelo autor, a etnografia não se concentra apenas nos momentos rituais, grande parte de seu aprendizado sobre o Jarê, afirma Banaggia, deu-se ao acompanhar o cotidiano das pessoas.

Nos termos do próprio autor, a etnografia em questão construiu-se a partir de "uma peregrinação comportando distintas polifonias orientadas, a cada capítulo, pela condução de alguma pessoa em particular" (:13). Essas pessoas, amigos, conforme denomina Banaggia, não configuram bons exemplos generalizáveis dos assuntos a serem tratados em cada capítulo. Muito pelo contrário, esses personagens apresentam dissenções e continuidades entre os assuntos tratados. E, assim, a obra de Banaggia destaca-se por sua narrativa, em que vários fios vão sendo tecidos paralelamente, mas que em seu todo compõem uma descrição rica que consegue apresentar ao leitor a própria estrutura de transformacionalidade proposta por Lévi-Strauss. A ideia de transformacionalidade aponta para uma estrutura que possui em si mesma a disposição para a transformação constante de alguns elementos internos, mantendo-se a estrutura. Essa transformação, conforme destaca Banaggia, possui determinados preceitos que, dessa forma, contribuem para a manutenção das forças do Jarê.

Além de seu valor literário, o livro de Banaggia merece destaque por se localizar contextualmente num campo de estudos ainda incipiente da antropologia da religião, que aponta para as relações que se estabeleceram entre indígenas e afrodescendentes num contexto cosmopolítico específico. Com isso, dá continuidade aos estudos comparativos de Bastide e, ao mesmo tempo, avança algumas questões inspi- 
rado na proposta transformacional de Lévi-Strauss. As três obras que ficaram conhecidas como as mitológicas de Claude Lévi-Strauss analisam a variação dos elementos e a permanência das relações existentes dentro da cosmologia indígena na América do Sul e Central. Assim, Banaggia caminha no sentido do desenvolvimento do que ele próprio afirma em seu texto que ainda está por ser produzido: as ritológicas, algo próximo de um esforço comparativo entre as religiões de matriz africana, da mesma maneira que a obra de Lévi-Strauss entre os indígenas, mas voltada ao ritual.

Cada capítulo inicia com uma frase que se refere à figura principal deste, assim o autor procura dar voz aos interlocutores buscando, como ele afirma, "operar uma inversão que possibilite que os mecanismos do pensamento antropológico sejam afetados por aquilo que as pessoas com quem se estuda dizem e demonstram a respeito da empreitada e de seus pressupostos" (:13). O autor oferece uma descrição detalhada dos sujeitos e dos fatos, buscando oferecer aos leitores a maior riqueza de detalhes possível e, deste modo, promover ao leitor a oportunidade de desenvolver suas próprias interpretações dos relatos.

Outra importante contribuição da obra aos estudos da religião é o exercício que o autor se propõe a desenvolver acerca do tema da crença. Esta não é colocada em questão, como em nossos termos modernos de verdade dos fatos por oposição à imaginação. A crença no Jarê não depende de postulações sobre a existência dessa religião, pois sua existência é dada; crer no Jarê para os sujeitos de Banaggia significa dar crédito às forças do Jarê. Como a existência não está em questão, a crença refere-se à permissão de reconhecer e contar com suas forças ou não. Assim, Banaggia simetriza sua relação com seus interlocutores: "[...] não se trata simplesmente de existirem ou não existirem, mas de existir com mais ou menos intensidade, num gradiente que vai das forças mais potentes e perenes às que terminam por desaparecer, quiçá por completo” (:253).

No primeiro capítulo, "Pisar", através de Seu Gilson, que trabalhava como garimpeiro apenas esporadicamente, sendo sua ocupação principal o serviço no banco local, a história do garimpo é entremeada com algumas concepções importantes que compõem o chegar em Lençóis. O verbo pisar, na região, é indicativo de caráter dentro da linguagem dos garimpeiros: quem pisa firme é de confiança e sabe escolher os caminhos. Nesse sentido, Banaggia relata sua própria chegada em campo e seu processo de estabelecimento de relações de confiança, além de outros processos de relações de confiança entre a população e estrangeiros, instituições, Estado, a partir do conceito nativo.

No segundo capítulo, "Dançar", o verbo introduz propriamente o Jarê através da perspectiva de Elias, um intelectual autodidata e um dos melhores amigos de Banaggia em seu campo, como ele próprio afirma. Recheado de conflitos e inconstâncias, o próprio interlocutor do capítulo reflete a dança do Jarê em que se relacionam forças diversas que espaço-temporalmente afetaram o modo de viver negro e, por consequência, seu modo de se relacionar com o mundo. $\mathrm{O}$ autor procura discutir como o poder público se coloca em relação com as questões socioculturais da popu- 
lação e como elementos diversos, como a capoeira, a bebida e a relação com outros setores sociais, como a academia, agenciam e subvertem a ordem social e, em correlação, a ordem da dança do Jarê.

O terceiro capítulo, "Tombar", conta-nos histórias do renomado mestre de Jarê Pedro de Laura, através de Sandoval, seu filho, que, mesmo não recebendo as entidades e não possuindo a "força" para se tornar sucessor de seu pai, se esforça por manter viva a Casa de Ogum. Conforme muitos dos amigos de Banaggia na pesquisa, Pedro de Laura foi o maior líder de Jarê da região, e sua força permanece mantendo firme a Casa de Ogum, mesmo sob condições adversas após sua morte. Neste capítulo, são apresentadas as diversas estratégias para mobilizar e vitalizar as forças do Jarê. A constituição da associação dos Jarês, liderada por Sandoval, e os tocadores de Jarê que são os grandes responsáveis por manterem as entidades dançando e a festa acontecendo são algumas dessas estratégias. Banaggia ainda aponta a contradição existente entre a proibição de registros fotográficos e audiovisuais a priori, mas que ao longo de seu campo figuraram como mais uma das estratégias. Segundo o autor, com o estabelecimento da confiança, tais recursos acabam sendo, até mesmo, solicitados pelos membros da casa como forma de registro que valorize e resgate as forças do Jarê.

A transmissão do saber dentro do Jarê, destaca o autor, precisa ser percebida a partir de uma lente mais ampla, que não esteja determinada pelos "nossos" parâmetros de conhecimento e transmissão do saber. As fotografias e vídeos, assim como as proibições ou a agência de Pedro de Laura em determinados momentos, apontam para uma forma de transmissão de saber própria do Jarê.

O quarto capítulo, "Levantar", valoriza as continuidades visíveis através do movimento espiral oferecido pela descrição de Banaggia do Jarê. Se é preciso pisar firme para transmitir a credibilidade necessária, se dançar é central para a festa do Jarê, e se tombar é uma forma de fazer surgir outras maneiras de se manter a força do Jarê, levantar é propagar a estrutura de maneira transformadora a partir das tramas, disputas, confidências que compõem este universo. Levantar o Jarê, após cada tombo, propagando sua força através da oralidade e da manutenção da relação de pessoas e caboclos, é parte deste processo sem fim de dançar o Jarê.

Por fim, na Conclusão, "Voltar", Gabriel Banaggia parece buscar retomar os procedimentos acadêmicos para refletir como o conhecimento advindo do Jarê pode recompor nosso próprio conhecimento. No esforço de simetrização, os aprendizados da experiência do autor são colocados em diálogo com os pressupostos da antropologia num esforço de se desenvolver uma reflexão composta por múltiplas perspectivas, do autor, dos interlocutores, dos caboclos, do Jarê e da Academia. Reflexão essa que aponta para a diversidade dos mundos e para a precariedade das definições. O Jarê oferece um outro mundo, regido por outras leis, e nesse mundo não existem definições essenciais: a transformação para a manutenção é o que se mantém.

Apresentando um desenho que não possui um fio condutor cronológico, mas um encontro de agenciamentos de várias ordens que compõem momentos singulares, 
Banaggia parece argumentar em favor de uma estrutura que existe e persiste em um movimento contínuo de abertura para o outro, para o novo, para o inesperado, dando a sensação de ser virtualmente possível lidar com qualquer situação que se apresente dentro do Jarê.

A ideia de estrutura de transformacionalidade em que Banaggia sustenta sua descrição deixa-nos algumas questões. Com a transformação como inerente à estrutura do Jarê, torna-se difícil uma ideia mais clara e definida do que se trata essa manifestação, bem como oferece uma ideia infinita sobre sua perpetuação, já que o autor não apresenta limites ou definições específicas. É importante considerarmos que a relação hierárquica entre brancos e negros também se propaga nessa estrutura transformacional, além de não serem mencionados pelo autor limites ou variações que desloquem de fato a relação secularmente colonizadora existente entre negros e brancos. A transformacionalidade abre portas à diversas forças externas, como, por exemplo, o Neopentecostalismo crescente na região, mas que, no entanto, não é desenvolvido pelo autor. A descrição do Jarê de Banaggia é certamente rica e oferece vários fios soltos, ou linhas de fuga, para usarmos a inspiração teórica do autor, mas, justamente por isso, mostra-se ainda como um campo promissor para o desenvolvimento de novas pesquisas que possam contribuir para esta sensação de falta de contorno do leitor.

Iacy Pissolato Silvera* (iacyps@gmail.com)

Marina Guimarães Vieira** (marinaguimaraesvieira@gmail.com)

* Doutoranda em Antropologia no Programa de Pós-Graduação em Antropologia da Universidade Federal da Bahia (UFBA), Salvador, BA, Brasil; Pesquisadora do Núcleo de Pesquisa Observabaía, UFBA; Mestra em Antropologia Social pelo Programa de Pós-Graduação em Antropologia da Universidade Federal de Minas Gerais (UFMG), Belo Horizonte, MG, Brasil.

** Professora Adjunta do Departamento de Antropologia e do Programa de Pós-Graduação em Antropologia da Universidade Federal da Bahia (UFBA), Salvador, BA, Brasil; Doutora em Antropologia Social pelo Programa de PósGraduação em Antropologia Social do Museu Nacional da Universidade Federal do Rio de Janeiro (UFRJ), Rio de Janeiro, RJ, Brasil. 